\title{
Improving Pediatric Vaccination During Covid19 Pandemic, in PHC, Riyadh, Saudi Arabia
}

\section{Medhat Maher*, Abdelaziz AIRasheed, Abood Alabood, Azzam Alotaibi, Tarek Elsaid, Maha Bassim, Fawzyia Altassan, Tariq Alhajlah, Sultan Almutairi and Mostafa Kofi}

Family and Community Medicine Department, Prince Sultan Military Medical City, PSMMC, Riyadh, Saudi Arabia

*Corresponding Author: Medhat Maher, Consultant, F\&CM Dept., Prince Sultan

Military Medical City, Riyadh, Saudi Arabia. E-mail: mohamedm@psmmc.med.sa
Received: October 21, 2021

Published: December 09, 2021

(C) All rights are reserved by Medhat Maher., et al.

\section{Abstract}

Background: Pediatric vaccination is mandatory program to control vaccine preventable diseases and in such cases that hinder its activity; in which conditions there is increased morbidity and mortality due to these vaccine preventable diseases [1]. Routine vaccination of children must remain a priority even during the covid-19 pandemic. All countries could experience outbreaks of vaccine preventable diseases if uptake of routine vaccinations fall, undoing decades of progress. Vaccination has been one of the most effective interventions in driving down infant mortality to historically low levels worldwide. For us at PHC, of the Family and Community Medicine Dept. PSMMC developed and promoted the vaccination of children uses the home visits pediatric vaccination, this work describes the success story of use of home visits pediatric vaccination to catch up vaccination coverage during the sever effects of COVID19 pandemic.
\end{abstract}

Methods: The study aimed to System changes, so can the vaccination program to continue and catch up the vaccination coverage after severance due to the impact of Covid19 pandemic Developing new booking software in the hospital web site based on patient geographical distribution, age of the child and vaccination required. For the parents to log in and register their child Patient affair and nursing will access the web site and distribute the registry according to geographical area prepare the team who will visit patient at home to be consisted of Physician, nurse and nurse assistant

Results: This graph shows that the number of vaccinated children at Alwazarat center has dropped significantly to zero starting from first week April 2020 (blue line), and stayed at the same level until first week of June 2020; which coincided with the start and peak period of OVID-19 pandemic. It also shows that the initiative of home vaccination was launched at second week of April (red line) and took off with more than 7 consecutive points during April through June 2020.

Conclusions: System changes to Developing new booking software in the hospital web site based on patient geographical distribution, age of the child and vaccination required to improve the patient access to care to log in and register their child. Integrated this program with healthcare team providers to facilitate the child home vaccination during Covid-19 pandemic and to allocate resources with continuity of care considering a safe procedure of vaccination at patient house,

Keywords: COVID-19; Pediatric Vaccination; Vaccination During Pandemic; Safe Handling of Home Vaccination

\section{Introduction}

The spread of COVID19 highly affected the health of the community as whole. Including the pediatric age group that needs visits to the primary health care center for their routine childhood vaccinations. Complete, timely vaccination protects and confers benefits across the whole of childhood [2]. Children's visits to emergency departments fell by over $90 \%$ during April 2020. Parents have expressed concerns about overburdening the NHS and 
fear of exposure to covid-19 when attending for vaccination [3]. General practitioners, practice nurses, midwives, and health visitors are well positioned to counsel prospective and new parents about vaccination. In areas of low uptake, contacting parents and pregnant women directly may be valuable, as conversations with a trusted healthcare professional can influence vaccination decisions [4]. Vaccine uptake in primary care is highest when parents feel safe and are given timely information that vaccines are due, and when healthcare staff have systems to ensure robust call and recall [5]. Primary care has risen to the challenges posed by covid-19 by enforcing triage to ensure safe distancing and by introducing hygiene measures and protective equipment to reduce infection risk. Some general practices have adopted drive-in vaccine clinics to reduce face-to-face contact with parents [6]. Parents may hesitate to bring their children to receive their vaccination in the primary health care center to avoid the possibility of contracting the infection which will lead to missing scheduled vaccines. On reviewing the missed vaccination appointment in the center, it was found that $100 \%$ of scheduled appointments for vaccination is missed. So, it was planned to recover and instead of giving the vaccination on site in the center in the well-baby clinics, the vaccination will be given for legible children at home. This case report is on the health system research to improve the coverage rate even with a Hugh and unprecedented challenge such as Covid19 pandemic.

\section{Problem description}

Coronaviruses are a large family of RNA viruses that cause illnesses ranging from the common cold to more severe diseases. The new strain of coronavirus was identified in December 2019 and has been named by the International Committee on Taxonomy of Viruses (ICTV) as Severe Acute Respiratory Syndrome Corona Virus-2 (SARS-CoV-2). The WHO has named the disease associated with SARSCoV-2 Infections as Corona Virus Disease 2019 (COVID-19). The COVID-19 pandemic is affecting the whole world health care systems including Saudi Arabia. According to the KSA Ministry of Health, total number of confirmed cases of COVID-19 is approaching 350,000 cases (beginning of November 2020). Dealing with the surge of the COVID-19 pandemic patients in the health care facilities needs proper ways to effectively detect the patients with flu symptoms and prevent the transmission of the infection to the other patients and the health care workers in the same time. Triage is defined as "The sorting out and classification of patients or casualties to determine priority of need and proper place of treatment" [1].

Triage is particularly important to separate patients likely to be infected with the pathogen of concern. In 2017 the Saudi Ministry of Health released a visual triage system with scoring to alert healthcare workers in emergency departments (EDs) and hemodialysis units for the possibility of occurrence of MERS-CoV infection [3] visual triage play very crucial role for prevention and control of MERS CoV/H1N1 among health care professionals [2].

\section{Rationale}

Proper handling of patient during covid19 pandemic contributes toward early detection and risk reduction for the patients and health care workers attending the primary health care facility. Visual triage has a crucial role in isolating patients that can potentially transmit infections to other patients or healthcare professionals. The inability to detect the patient suffering from COVID19 contributes to the spread of infection in the center.

\section{Project objectives}

- $\quad$ To restore routine childhood vaccination system during COVID 19 pandemic.

- To compensate missed doses through the catch-up program

- $\quad$ To protect children, parents and health care professionals from COVID 19 infections.

- $\quad$ Prevents outbreak of measles and other vaccination viruses.

\section{Materials and Methods}

- $\quad$ Research Design: Health system research case report.

- Intervention Methods: The study aimed to System changes, so can the vaccination program to continue and catch up the vaccination coverage after severance due to the impact of Covid19 pandemic Developing new booking software in the hospital web site based on patient geographical distribution, age of the child and vaccination required. For the parents to log in and register their child Patient affair and nursing will access the web site and distribute the registry according to geographical area prepare the team who will visit patient at home to be consisted of Physician, nurse and nurse assistant Table 1 and Picture 1 and 2. 
Organizing the team

\begin{tabular}{|c|c|c|}
\hline Requirement & Division & $\begin{array}{c}\text { Roles and } \\
\text { Responsibilities }\end{array}$ \\
\hline Medical Staff & $\begin{array}{l}\text { FCM and Pedi- } \\
\text { atrics Team }\end{array}$ & $\begin{array}{l}\text { Put the plan, define infec- } \\
\text { tion control measures, } \\
\text { educate staff, resource } \\
\text { allocation, staff education, } \\
\text { public announcement, } \\
\text { Order vaccine to be given }\end{array}$ \\
\hline $\begin{array}{l}\text { Nursing and } \\
\text { Coordinators }\end{array}$ & Nursing & $\begin{array}{l}\text { Patient Identification and } \\
\text { administration of vaccines, } \\
\text { and recording the vac- } \\
\text { cinated children }\end{array}$ \\
\hline $\begin{array}{l}\text { Emergency } \\
\text { equipment }\end{array}$ & Nursing & $\begin{array}{c}\text { O2 Cylinder, AED, Ambu } \\
\text { bag and medications }\end{array}$ \\
\hline Patient Affairs & Patient Affairs & $\begin{array}{c}\text { Booking of home vaccine } \\
\text { list }\end{array}$ \\
\hline $\begin{array}{l}\text { Engineering and } \\
\text { Maintenance }\end{array}$ & $\begin{array}{l}\text { Engineering } \\
\text { Unit }\end{array}$ & $\begin{array}{l}\text { For emergency interven- } \\
\text { tion }\end{array}$ \\
\hline Transportation & $\begin{array}{c}\text { Transportation } \\
\text { Department }\end{array}$ & $\begin{array}{l}\text { For transportation to loca- } \\
\text { tion of patients }\end{array}$ \\
\hline Quality team & FCM & $\begin{array}{l}\text { Patient safety and IPC } \\
\text { recommendation }\end{array}$ \\
\hline Pharmacy & Pharmacy Unit & Vaccination supply \\
\hline
\end{tabular}

Table 1

Visit changes according to schedule planned and confirmation with families.

Review and list all legible children for vaccination according the vaccination

Schedule review and list all booked children in the center for vaccination who missed their vaccination during COVID19 Educate staff about infection control measures at patient homes. Allocate resources, 10 cars equipped with emergency medication bags, and oxygen supply, infection control measures Modify the allocated cars to fit the pediatric EX area in the back of the car. distribute mobile phones for the teams to communicate with the center and patient family Complete the vaccination registry for vaccinated children Implement the plan Apply infection control precautions both in the health care center and during the home visits Document each visit and the outcomes of each visit (whether the patient received the vaccine or not) Review The statistics of the vaccinated children daily.

Continue the service while COVID 19 pandemic is still on.

\section{Results and Discussion}

Figure 1 shows that the number of vaccinated children at Alwazarat center has dropped significantly to zero starting from first week April 2020 (blue line), and stayed at the same level until first week of June 2020; which coincided with the start and peak period of OVID-19 pandemic. It also shows that the initiative of home vaccination was launched at second week of April (red line) and took off with more than 7 consecutive points during April through June 2020; peaking at more than 700 vaccinated children per week; then at beginning of June the on-site vaccination began to resume (when curfew measures started to loosen up), and both approaches were then applied until the first week of October were on site vaccination regained dominance (reaching 700 vaccinated children per week) till the time of writing this report. It is important to notice that home vaccination is still running as some of the parents are still requesting it for a variety of social reasons.

\section{Conclusions}

System changes to Developing new booking software in the hospital web site based on patient geographical distribution, age of the child and vaccination required to improve the patient access to care to log in and register their child. Integrated this program with healthcare team providers to facilitate the child home vaccination during Covid-19 pandemic and to allocate resources with continuity of care considering a safe procedure of vaccination at patient house.

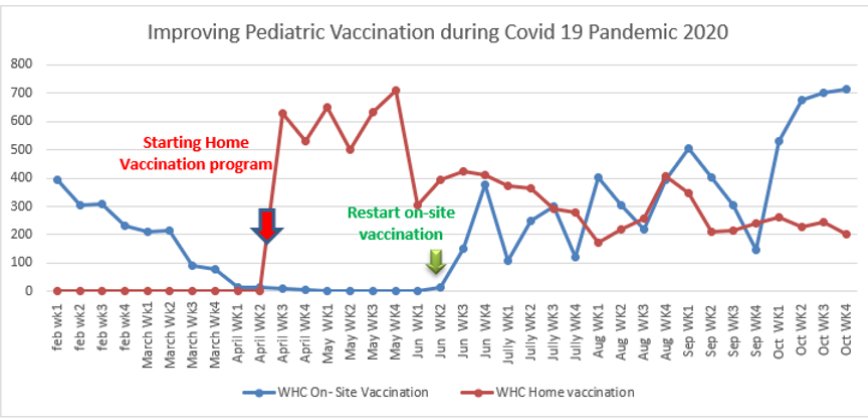

Figure 1

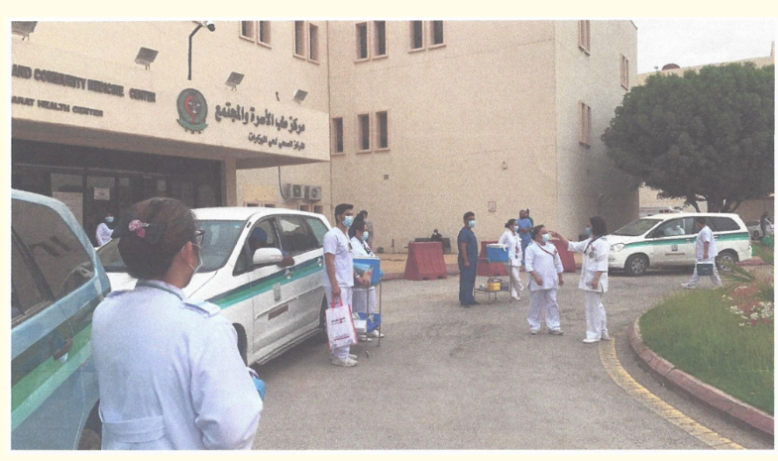

Picture 1: The picture shows the head nurse and the nurse-coordinator while inspecting and checking the teams in the morning before heading to the home visits to ensure the availability of the required medical equipment, supplies and vaccines for patient. 


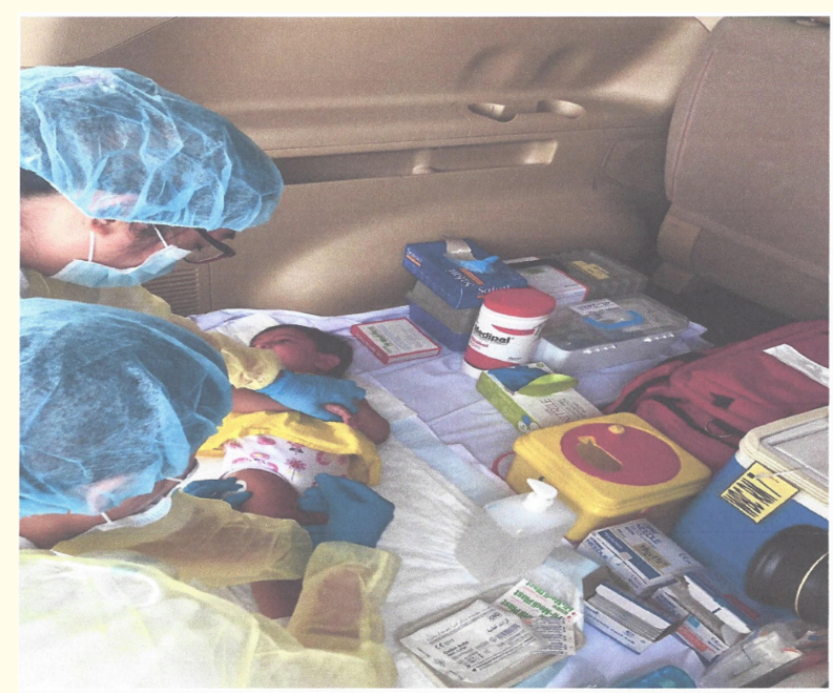

Picture 2-3: The nursing team while giving the vaccine doses inside the vehicles that have been modified for this, noting that all medical supplies are available and the nursing team wearing the personal protective equipment to reduce the spread and transmission of any infection.

\section{Bibliography}

1. Cecil E., et al. "Impact of preventive primary care on children's unplanned hospital admissions: a population-based birth cohort study of UK children 2000-2013". BMC Medicine 16(2018):151.

2. Saxena S., et al. "Routine vaccination during covid-19 pandemic response". BMJ 369 (2020): m2392.

3. Public Health England. "Emergency department syndromic surveillance system: England”. Week 16 (2020).

4. Leask J., et al. "Communicating with parents about vaccination: a framework for health professionals". BMC Pediatrics 12 (2012): 154.

5. Williams N., et al. "Primary care strategies to improve childhood immunization uptake in developed countries: systematic review". JRSM Short Report 2 (2011): 81.

6. Hussain D. "Childhood immunizations: how a practice reduced face-to-face time”. Nursing in Practice (2020).

\section{Assets from publication with us}

- Prompt Acknowledgement after receiving the article

- Thorough Double blinded peer review

- Rapid Publication

- Issue of Publication Certificate

- High visibility of your Published work

Website: www.actascientific.com/

Submit Article: www.actascientific.com/submission.php

Email us: editor@actascientific.com

Contact us: +919182824667 